Research Article

\title{
Recovery of Exhaust Waste Heat for ICE Using the Beta Type Stirling Engine
}

\author{
Wail Aladayleh and Ali Alahmer \\ Department of Mechanical Engineering, Tafila Technical University, P.O. Box 179, Tafila 66110, Jordan \\ Correspondence should be addressed to Ali Alahmer; a.alahmer@ttu.edu.jo
}

Received 26 August 2014; Accepted 9 December 2014

Academic Editor: Guobing Zhou

Copyright ( 2015 W. Aladayleh and A. Alahmer. This is an open access article distributed under the Creative Commons Attribution License, which permits unrestricted use, distribution, and reproduction in any medium, provided the original work is properly cited.

\begin{abstract}
This paper investigates the potential of utilizing the exhaust waste heat using an integrated mechanical device with internal combustion engine for the automobiles to increase the fuel economy, the useful power, and the environment safety. One of the ways of utilizing waste heat is to use a Stirling engine. A Stirling engine requires only an external heat source as wasted heat for its operation. Because the exhaust gas temperature may reach 200 to $700^{\circ} \mathrm{C}$, Stirling engine will work effectively. The indication work, real shaft power and specific fuel consumption for Stirling engine, and the exhaust power losses for IC engine are calculated. The study shows the availability and possibility of recovery of the waste heat from internal combustion engine using Stirling engine.
\end{abstract}

\section{Introduction}

Today, the energy researches take a wide place in the world; the automobile is so significant that it consumes more than half of the total energy used by all types of transportation combined. Numerically, the energy consumption of automobiles accounts for $52 \%$ of all energy used by the entire transportation; less than $35 \%$ of the energy in a gallon of gasoline reaches the wheels of a typical car; the remaining heat is expelled to the environment through exhaust gases and engine cooling systems [1]. Figure 1 illustrates the energy losses of internal combustion engine (ICE). The figure shows the thermal losses take $60 \%$ approximately, and $33 \%$ of the power is expelled with exhaust gases; in another mean twothirds of our fuels' money was spent in the environment. Since most of the energy consumed by an internal combustion engine is wasted, capturing much of that wasted energy can provide more power and efficiency. Many researchers examine how to utilize that lost energy and many methods were used such as thermoelectric generation, piezoelectric generation, thermionic generation, thermophotovoltaic, and mechanical turbo [2]. But these entire components were considered as electric or electronic methods and they cannot give largest power at high temperature. Another method now used to recover the heat from exhaust gas is called organic Rankin cycle (ORC). Figure 2 is based on the steam generation in a secondary circuit using the exhaust gas thermal energy to produce additional power by means of a steam expander. The principle working of the organic Rankin cycle is the same as that of Rankin cycle: the working fluid is pumped to a boiler where it is evaporated, passed through an expansion device (turbine or other expander), and then passed through a condenser heat exchanger which it is finally recondensed $[3,4]$. Another method to recover exhaust heat is by the use of the Stirling engine technique. This method has more activity and it is considered an external combustion engine to produce mechanical work. The recovery and utilization of waste heat not only conserve fuel, usually fossil fuel, but also reduce the amount of waste heat and greenhouse gases damped to environment [2]. The use of Stirling engine has many advantages which can be summarized as follows [5-7]: high potential efficiency up to $45 \%$, reversible operation, cleaner emissions, quiet operation, low vibrations, low maintenance, smooth torque delivery, and ability to run at different fuels; finally Stirling engine does not have valves, carburetor, ignition system, or boilers. 


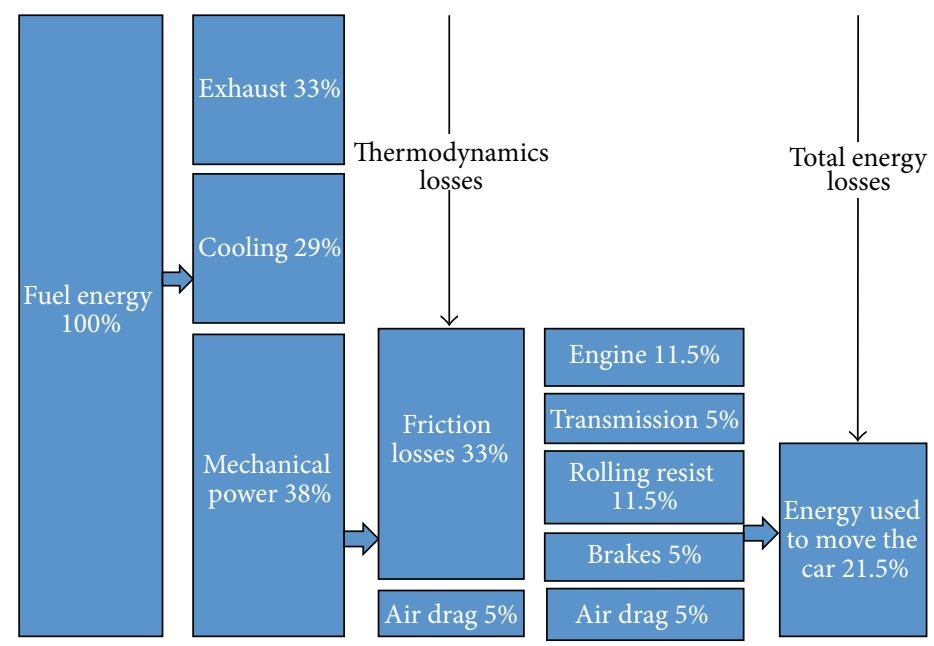

FIGURE 1: Energy losses of internal combustion engine.

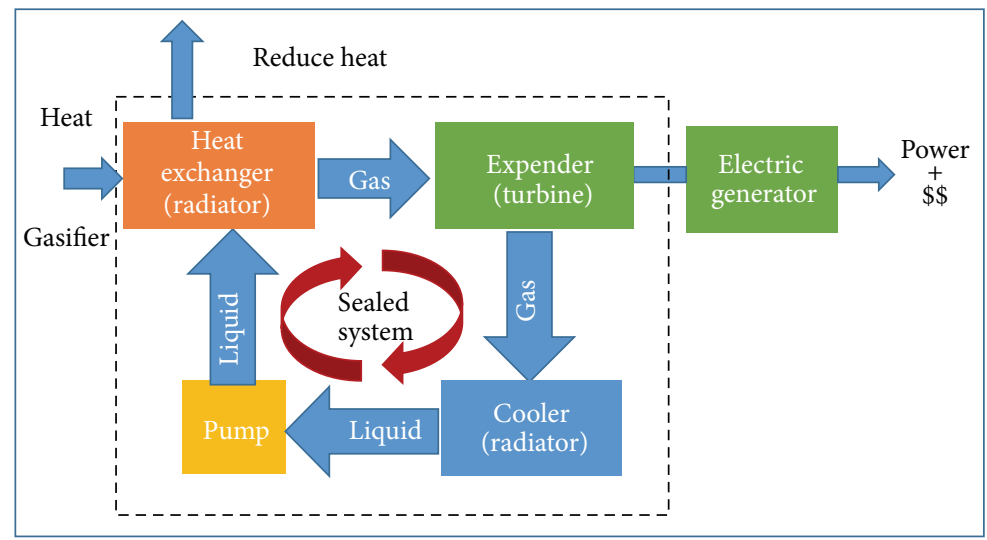

FIgURE 2: Organic Rankin cycle (ORC).

On the other side the main disadvantages and limitations can be concluded as long start-up time at cold starting, typically not self-starting, and finally being quite large and heavy.

The main objectives of this paper could be summarized in two points: using Stirling engine to recover the waste power through exhaust manifold to generate electrical power and also showing the effect of raising the entire operating pressure for Stirling engine to get more power in practical size for the automobile and internal combustion engine.

The body structure of this paper starts by highlighting objectives, advantages, limitations, and related research in Section one. The main factors that have an effect on the performance of Stirling engine were displayed in Section two. Thermodynamic model analysis in terms of Schmidt cycle, waste exhaust recovery, Stirling engine power, and exhaust temperature profile were covered in Section three. Our proposed exhaust's heat recovery system in Section four follows. Section five presented the experimental methodology and setup. The calculation and results were depicted in Section six. Finally, Section seven summarizes the entire paper and shows the main conclusion.

\section{Stirling Engine Effective Factors}

Usually the design point of a Stirling engine will be somewhere between the two limits of (1) maximum efficiency point and (2) maximum power point. There are many factors that may affect the out power and mechanical efficiency for the Stirling efficiency, which can be concise as the following. (i) Swept volume: the area under the $P-V$ diagram indicates to the network that if the volume expands the power will be increased; (ii) regenerator efficiency: the regenerator has mesh wires to store the heat while the working gas transfers between the hot side and cold side; theoretically if the engine does not have a full regenerative, the major trouble will be in the stream flow losses through the regenerator; (iii) mean pressure: it is the average pressure inside the engine at the maximum and lower temperatures; the problem appeared when the inside pressure is more than the atmospheric pressure; unbalance on the piston will occur; (iv) working gas: the type of gas in the Stirling engine takes a major factor; to get more power, the filled gas must have high specific heat capacity so that the gas will gain and lose the heat rapidly; 
then the piston is moving rapidly to produce a positive speed [5]. The hydrogen has the lowest molecular weight so it has great efficiency but low safety. Helium $(\mathrm{He}), \mathrm{N}_{2}$, and air were considered a working gas for Stirling engine; and finally (v) temperature difference: as any heat engine, the mechanical efficiency stands upon the hot temperature and cold temperature so more difference gives more efficiency.

\section{Thermodynamic Analysis}

3.1. Schmidt Cycle Analysis. The Schmidt cycle is defined as a Stirling cycle in which the displacer and the power piston or the two power pistons move sinusoidally and dead volumes are found. The assumptions upon which the Schmidt analysis was based are as follows [8]: (i) sinusoidal motion of parts; (ii) gas temperatures known and constant in all parts of the engine; (iii) absence of gas leakage; (iv) working fluid following perfect gas law; and finally (v) at each instant in the cycle the gas pressure being the same throughout the working gas.

In this paper the Schmidt cycle will be evaluated numerically. The performance of the engine can be calculated using $P-V$ diagram. The volume in the engine is calculated using the internal geometry. When the volume, mass of the working gas, and the temperature are decided, then the pressure is calculated using an ideal gas method in PV $=$ mRT equation.

Firstly, the volumes of the expansion and compression cylinder at a given crank angle will be determined. The instantaneous expansion volume $V_{E}$ is

$$
V_{E}=\frac{V_{S E}}{2}(1-\cos \theta)+V_{D E}
$$

where $V_{S E}$ is a swept volume of the expansion piston and $V_{D E}$ is an expansion dead volume under the condition. by

The instantaneous compression volume $V_{C}$ is determined

$$
V_{C}=\frac{V_{S E}}{2}[1-\cos \theta)+\frac{V_{S C}}{2}[1-\cos (\theta-\varphi)]+V_{D C}-V_{B}
$$

where $V_{S C}$ is a swept volume of the compression piston, $V_{D C}$ is a compression dead volume, and $\varphi$ is phase angle.

The total instantaneous volume is calculated in

$$
V=V_{E}+V_{R}+V_{C}
$$

In the Beta type Stirling engine, the displacer piston and the power piston are located in the same cylinder. When both pistons overlap, an effective working space is created. The overlap volume $V_{B}$ is

$$
V_{B}=\frac{V_{S E}+V_{S C}}{2}-\sqrt{\frac{V_{S E}^{2}+V_{S C}^{2}}{4}-\frac{V_{S E} V_{S C}}{2} \cos \varphi}
$$

The engine pressure $P$ based on the mean pressure $P_{\text {mean }}$, the minimum pressure $P_{\min }$, and the maximum pressure $P_{\max }$ is described in [8]:

$$
\begin{aligned}
P & =\frac{P_{\text {mean }} \sqrt{1-c^{2}}}{1-c \cdot \cos (\theta-A)}=\frac{P_{\max }(1-c)}{1-c \cdot \cos (\theta-A)} \\
& =\frac{P_{\min }(1+c)}{1-c \cdot \cos (\theta-A)},
\end{aligned}
$$

where

$$
\begin{gathered}
A=\tan ^{-1} \frac{v \sin \varphi}{t+\cos \varphi+1}, \\
S=t+2 t x_{D E}+\frac{4 t x_{R}}{1+t}+v+2 x_{D C}+1-2 x_{B}, \\
x_{B}=\frac{V_{B}}{V_{S E}}, \\
B=\sqrt{t^{2}+2(t-1) v \cos \varphi+v^{2}-2 t+1}, \\
B=\frac{B}{S}, \quad t=\frac{T_{C}}{T_{E}}, \quad v=\frac{V_{S C}}{V_{S E}}, \quad x_{D E}=\frac{V_{D E}}{V_{S E}}, \\
x_{D C}=\frac{V_{D C}}{V_{S E}}, \quad x_{R}=\frac{V_{R}}{V_{S E}},
\end{gathered}
$$

where $t$ is temperature ratio, $v$ is a swept volume ratio, and $x$ is dead volume ratio.

The net indicated work per cycle [8] is described by

$$
\begin{aligned}
W_{\text {net }} & =\frac{P_{\text {mean }} V_{S E} \pi c(1-t) \sin A}{1+\sqrt{1-c^{2}}} \\
& =\frac{P_{\min } V_{S E} \pi c(1-t) \sin A}{1+\sqrt{1-c^{2}}} \cdot \frac{\sqrt{1+c}}{\sqrt{1-c}} \\
& =\frac{P_{\max } V_{S E} \pi c(1-t) \sin A}{1+\sqrt{1-c^{2}}} \cdot \frac{\sqrt{1-c}}{\sqrt{1+c}} .
\end{aligned}
$$

3.2. Waste Heat Energy Calculation. The quantity of waste heat contained in an exhaust gas is a function of both the temperature and the mass flow rate of the exhaust gas:

$$
\dot{Q}=\dot{m} * c_{p} * \Delta T,
$$

where $\dot{Q}$ is the heat loss $(\mathrm{kJ} / \mathrm{s}) ; \dot{m}$ is the exhaust gas mass flow rate $(\mathrm{kg} / \mathrm{s}) ; c_{p}$ is the specific heat of exhaust gas $(\mathrm{kJ} / \mathrm{kg} \cdot \mathrm{K})$; and $\Delta T$ is temperature gradient in $\mathrm{K}$.

The mass flow rate of exhaust gas $\dot{m}_{E}$

$$
\dot{m}_{E}=\dot{m}_{f}+\dot{m}_{a}
$$

Mass flow rate of air $\left(\dot{m}_{a}\right)$ can be evaluated according to

$$
\dot{m}_{a}=\mu_{\gamma} * \rho_{a} * v_{s} * N * 2 .
$$

Mass flow rate of fuel $\left(\dot{m}_{f}\right)$

$$
\dot{m}_{f}=\frac{\dot{m}_{a}}{(A / F)_{\text {ratio }}} .
$$

The volumetric efficiency $\left(\mu_{\gamma}\right)$ has a range 0.8 to 0.9 . 


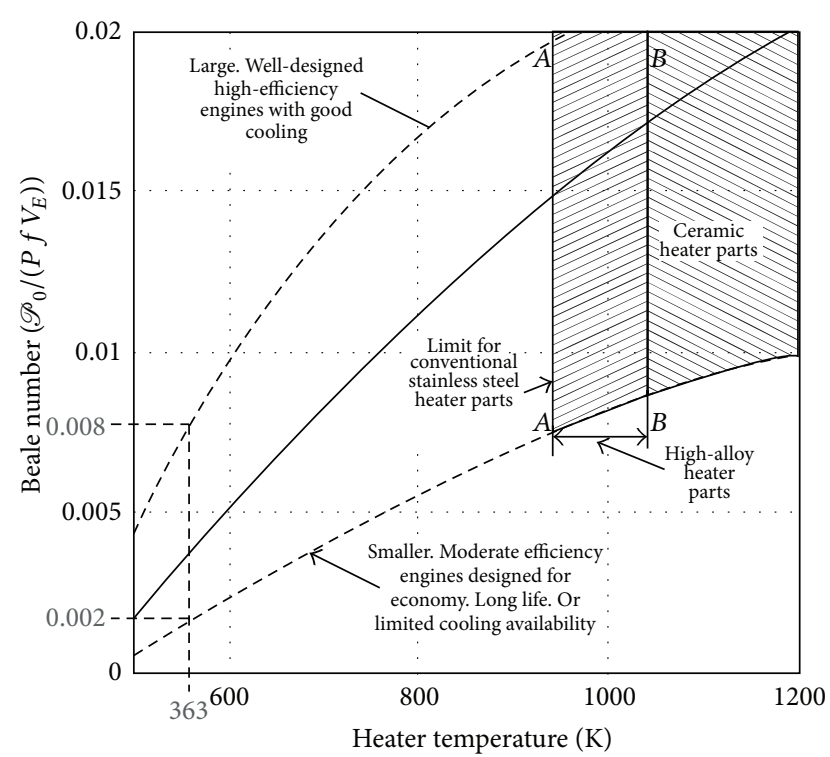

FIGURE 3: Graph of Beale number vs. heater temperature for a range of Stirling engines [5].

3.3. Engine Power Output. Power output can be estimated using a variety of methods which takes into consideration many things like temperature difference, operating speed and pressure, expansion and compression space volumes, and regenerator effectiveness. The Beale and West numbers were used to determine the Stirling engine power.

3.3.1. Beale Number. It is an empirical number that characterizes the performance of Stirling engine. It is used to estimate the power output of Stirling through relating an indicated power, $\mathscr{P}_{O}(\mathrm{~W})$, to mean pressure $P($ bar), operating frequency $f(\mathrm{~Hz})$, and expansion space volume $V_{E}\left(\mathrm{~cm}^{3}\right)$ with the Beale number $B_{n}$ :

$$
\mathscr{P}_{o}=B_{n} P f V_{E} .
$$

Beale number can be estimated from Figure 3, showing a graph plotted by measuring data from many Stirling engines. The solid line in the middle is typical of most Stirling engines while the upper and lower lines denote unusually high or low performing engines [5].

3.3.2. West Number. It is similar to the Beale number except it takes direct account of the temperature difference. The formula is expressed as

$$
\mathscr{P}_{o}=W_{n} P f V_{E}\left(\frac{T_{h}-T_{c}}{T_{h}+T_{c}}\right),
$$

where $W_{n}$ is the West number, which has an average value of $0.25-0.35$, and a higher number represents a more efficient engine.

3.4. Temperature Profile in Automotive Exhaust Systems. The flow rate and temperature profile of the burnt gases passing
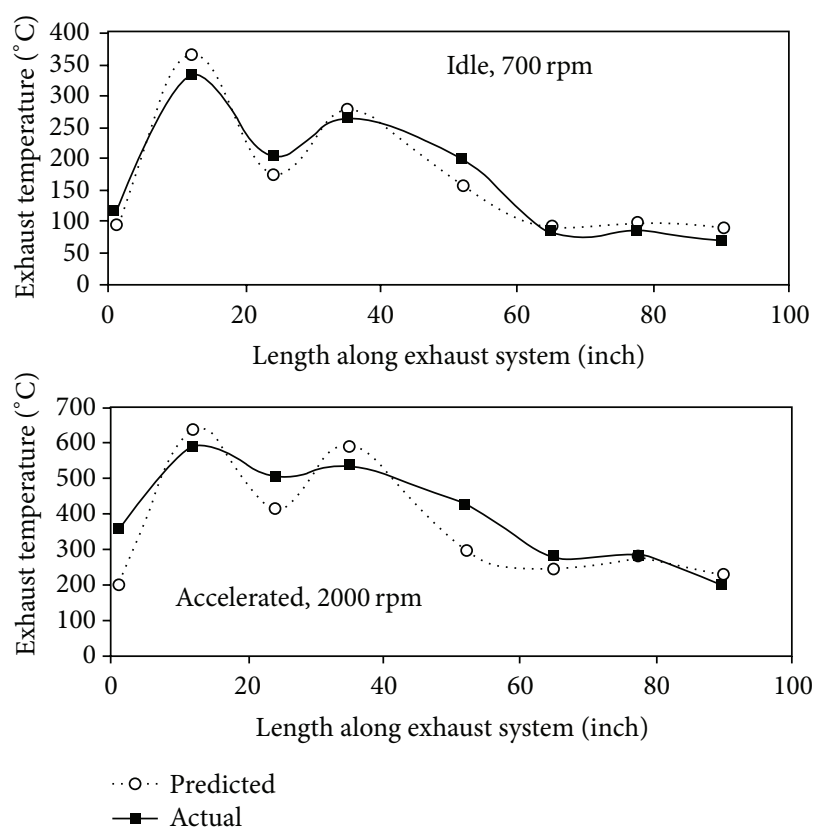

FIGURE 4: Illustration of the exhaust gas temperature versus tailpipe length [9].

through the exhaust system are required to determine the most effective location for Stirling engine placement. Figure 4 shows the comparison of the estimated and measured temperatures for almost identical runs along the exhaust line of the test vehicle for both idling and accelerated engine speeds [9]. The surface temperature measurements method was used in nearly stable conditions after initial warmup. Exhaust temperatures for idling conditions were much lower compared to accelerated conditions. When moving away from the exhaust valve, the gases temperatures will be decreased. Exhaust temperature varies with engine load; more loads or speed means more exhaust temperature due to decreasing in expansion cooling.

\section{Proposed Exhaust's Heat Recovery System}

Figure 5 presents the unit of heat recovery for exhaust system (3D/section) views. Stirling engine components are (1) exhaust gases outlet; (2) exhaust gases inlet; (3) hot heat exchanger; (4) displacer piston cylinder; (5) coolant jacket; (6) crank case container (to keep high pressure behind power piston); (7) displacer; (8) power piston; and finally (9) crank shaft and flywheel.

Afterwards, the exhaust gases leave the combustion chamber, they will enter through hot exchanger's pipe 1, and then they leave from heat exchanger pipe 2 and then to catalytic converter, muffler, and tailpipe.

Hot heat exchanger must be near to exhaust valve or isolate the inlet pipe in Rockwool to prevent the exhaust gases' heat escaping before it entered the heat exchanger. The coolant jacket is used to get difference in engine temperature also, to improve good contraction for working fluid for Stirling engine in cold side of Stirling engine; coolant jacket 


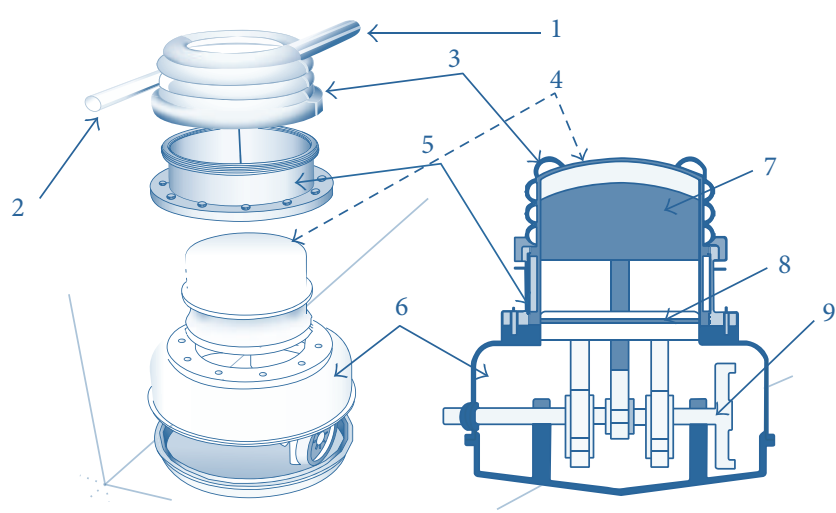

Figure 5: Exhaust's heat recovery unit.

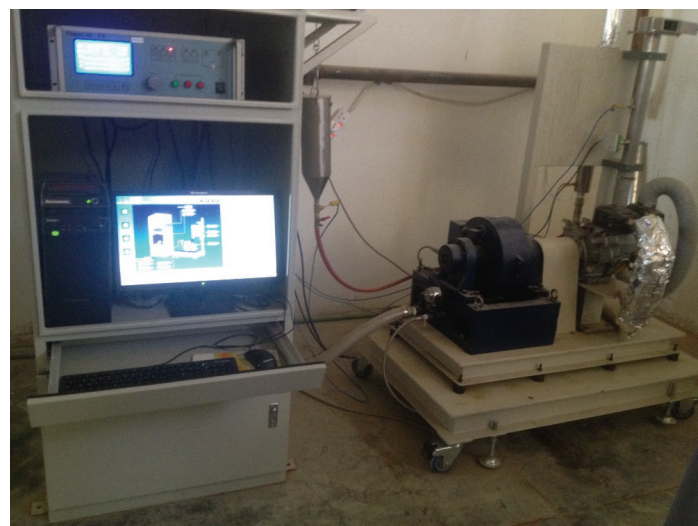

FIGURE 6: SI Robin engine single cylinder, air cooled and with directinjection.

must be connected directly with a separated radiator. The displacer owns a vertical hole with mesh material because of brief in engine size; the container also has compensated valve to modify entire pressure of the engine.

\section{Experimental Setup}

A number of experiments were carried out in Tafila Technical University in the automotive laboratories. A Robin engine single cylinder, air cooled and with direct-injection engine, was used in this work as shown in Figure 6. The engine specifications are listed in Table 1. To measure the gasoline engine torque, the engine was coupled to dynamometer. The reading of engine parameters was recorded after $135 \mathrm{sec}$ of engine operation and depicted in Table 2 . The Stirling engine was coupled to ICE. The specification of Stirling engine was listed in Table 3.

\section{Results and Calculations}

To evaluate the wasted exhaust power, the air and fuel flow through the combustion process should be estimated. From the recorded information during experiment in Table 2, the fuel consumption is $21.6 \mathrm{~g}$ in interval 135 seconds. So the
TABLE 1: Specifications and parameters of the internal combustion engine.

\begin{tabular}{lc}
\hline \multicolumn{2}{c}{ ICE specifications } \\
\hline Brand & Robin engines single cylinder \\
Model & EX13D-4 stroke \\
Displacement & $126 \mathrm{CC}$ \\
Max. output & $3.2 \mathrm{KW}$ at $4000 \mathrm{rpm}$ \\
Max. torque & $8 \mathrm{~N} . \mathrm{m}$ at $2500 \mathrm{rpm}$ \\
Fuel & Unleaded gasoline \\
Spark plug & NGK B4 (recommended) \\
Cooling & Air cooling \\
Lubricant & API/SE or SAE 10W-30 \\
\hline \multicolumn{2}{c}{} \\
\hline Bore & $58 \mathrm{~mm}$ \\
Stroke & $48 \mathrm{~mm}$ \\
Air intake duct diameter & $54.8 \mathrm{~mm}$ \\
Exhaust manifold diameter & $64 \mathrm{~mm}$ \\
\hline
\end{tabular}

TABLE 2: Readings of ICE powered by Jordanian gasoline/octane rate 95 after 135 seconds at beginning of the engine operation.

\begin{tabular}{lc}
\hline \multicolumn{2}{c}{ ICE reading } \\
\hline Exhaust gas temperature & $200^{\circ} \mathrm{C}$ \\
Ambient temperature & $24.5^{\circ} \mathrm{C}$ \\
Oil temperature & $85.8 \mathrm{C}$ \\
Fuel temperature & $23.8 \mathrm{C}$ \\
Engine speed & $2585 \mathrm{rpm}$ \\
Engine power & $2.3 \mathrm{KW}$ \\
Air flow speed & $1.5 \mathrm{~m} / \mathrm{s}$ \\
\hline
\end{tabular}

TABLE 3: Parameters and specifications of Stirling engine.

\begin{tabular}{lc}
\hline \multicolumn{2}{c}{ Stirling engine parameters } \\
\hline Engine configuration & Stirling engine-Beta type \\
Hot swept volume & $200 \mathrm{CC}$ \\
Cold swept volume & $150 \mathrm{CC}$ \\
Hot dead volume & $25 \mathrm{CC}$ \\
Cold dead volume & $20 \mathrm{CC}$ \\
Regenerator volume & $30 \mathrm{CC}$ \\
Mean pressure & $20 \mathrm{bars}$ \\
Hot side temperature & $200^{\circ} \mathrm{C}$ \\
Cold side temperature & $35^{\circ} \mathrm{C}$ \\
Phase angle & $90^{\circ}$ \\
Engine speed & $1500 \mathrm{rpm}(25 \mathrm{~Hz})$ \\
Working fluid & $\mathrm{Air}$ \\
\hline
\end{tabular}

fuel and air flow are $0.16 \mathrm{~g} / \mathrm{s}$ and $4.32 \mathrm{~g} / \mathrm{s}$, respectively. The brake power and recovery exhaust power are $0.901 \mathrm{~kW}$ and the percentage difference for exhaust and brake power is $61 \%$. The result of availability of heat recovery by Robin engine is 


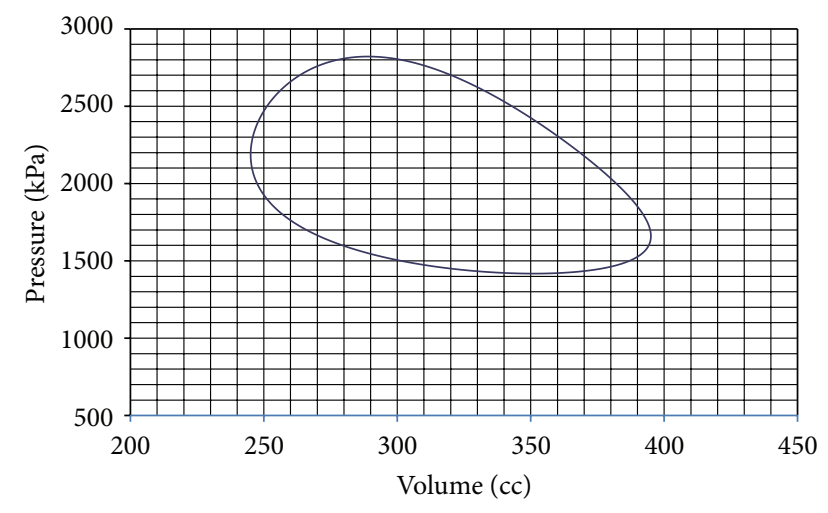

FIGURE 7: Relation between entire pressures and changing in volume for Stirling engine.

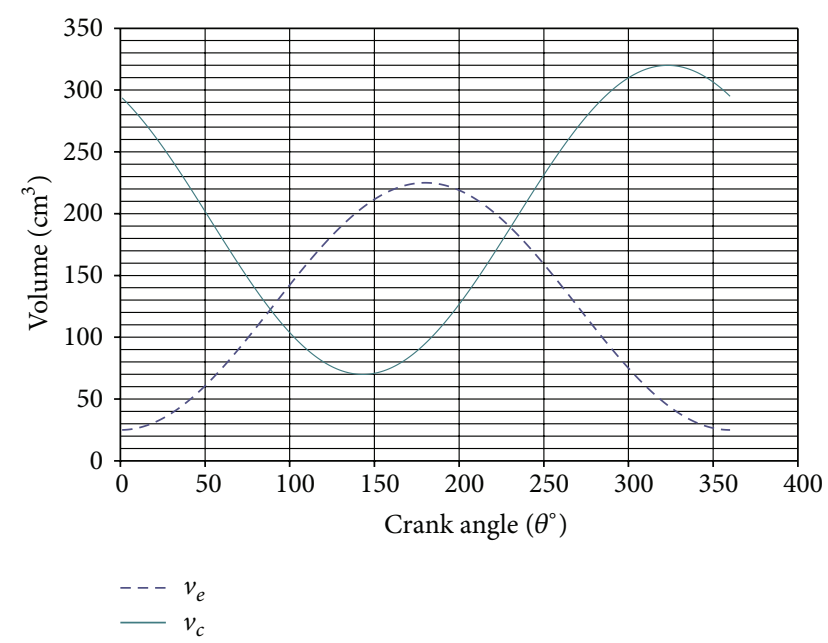

FIGURE 8: Relation for volume changing of expansion and contraction space versus crank angle.

similar to 04 Prius 1NZ-FEX and BMW M135i which give (58\% and $56 \%$, resp.) percentage difference.

Figure 7 represents the relation between entire pressures and changing in volume for Stirling engine, the curve being formed as cam lobe due to dead volume affected and nonsinusoidal motion for the drive mechanism; Schmidt cycle gives ideal assumption, else dead volume and nonsinusoidal motion, too. The area enclosed in $P-V$ curve was indicated work per one cycle. Figure 8 illustrates the relation for volume changing of expansion and contraction space with crank angle. From this diagram the location of the volumes of expansion can be determined and contraction space must be equal relatively to crank angle. Also it can be provided as an indication for critical point when the volume was converted or changed from increasing to decreasing or inverting versus crank angle. Figure 9 shows the relation between total volumes for Stirling engine versus crank angle. From this diagram the total volume changing relatively to crank angle can be determined; also the flow rate of working gas inside Stirling engine can be estimated at any instant. After that the flow losses through the engine can be evaluated. The

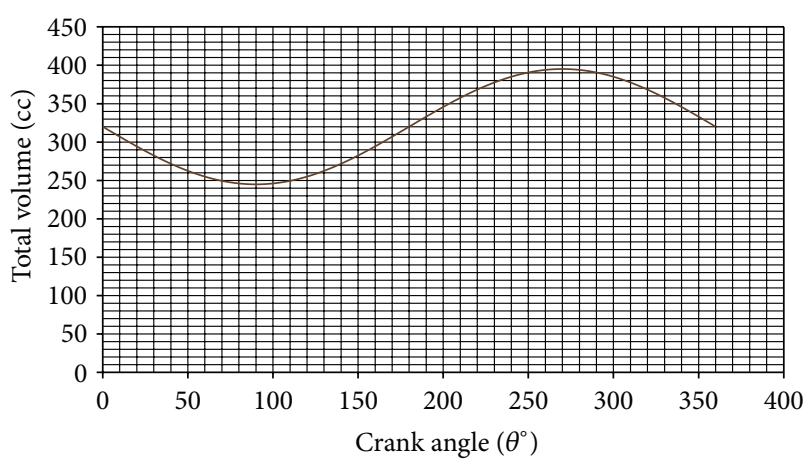

FIGURE 9: Changing of the total volume versus the crank angle for Stirling engine.

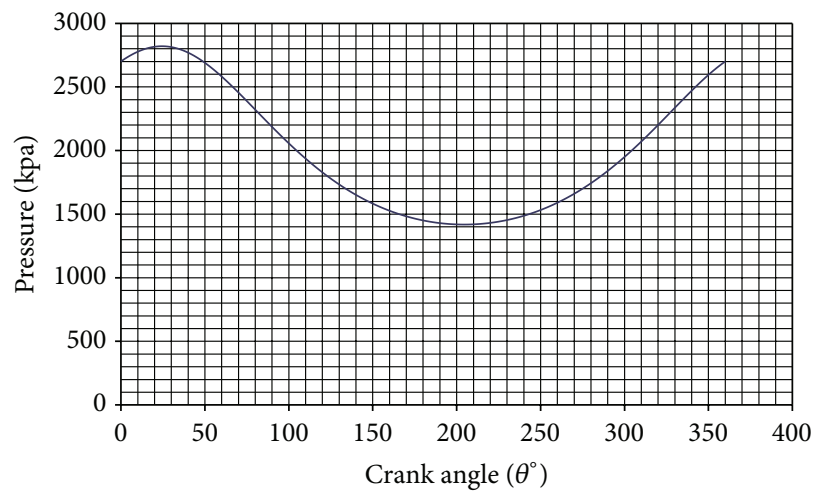

FIGURE 10: Changing of the pressure versus the crank angle for Stirling engine.

total pressure versus crank angle is depicted in Figure 10. The relation between pressure and total volume is inverse here. The expansion and contraction intervals cannot be determined precisely from $P-V$ diagram. But on the other side, the expansion and contraction can be easily evaluated from $V-\theta$ or $P-\theta$ diagram.

According to the Schmidt cycle, the ideal expansion work, pumping work, total network, and ideal net power are 88.5 J, $-56.6 \mathrm{~J}, 31.9 \mathrm{~J}$, and $0.772 \mathrm{~kW}$ at $1500 \mathrm{rpm}$, respectively. For estimation the real output (shaft power) for Stirling engine is $0.42 \mathrm{~kW}$ based on the Beale method. From Figure 3, the Beale number is nearly 0.0042 at heater temperature $200^{\circ} \mathrm{C}$. So, mechanical efficiency for Stirling engine is $51.8 \%$.

To determine the specific fuel consumption using Stirling engine, the following equation was used:

$$
\text { s.f.c. }{ }_{\text {with Stirling }}=\frac{\text { s.f.c. } \text { without Stirling }}{1+h} \text {, }
$$

where $h$ is lowering percentage for brake power; in this case it is equal to $18 \%$, so the s.f.c. with Stirling engine will lower to $15 \%$ of s.f.c. without Stirling engine. $h$ can be calculated by dividing real brake power for Stirling engine on brake power for IC engine:

$$
h=\frac{\mathscr{P}_{\text {br.sti }}}{\mathscr{P}_{\text {br.IC }}}
$$




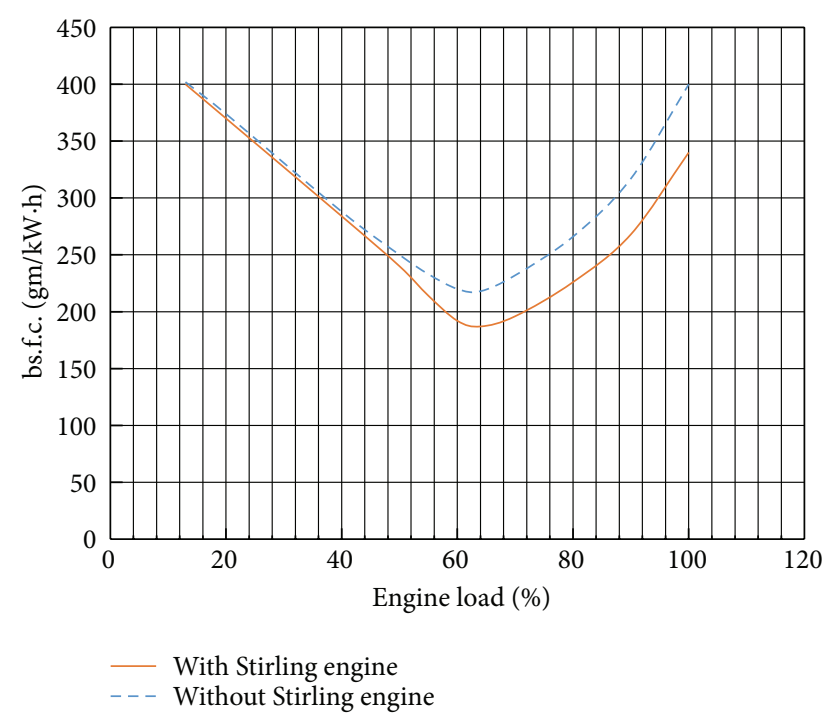

FIGURE 11: Showing brake specific fuel consumption without Stirling engine and with Stirling engine.

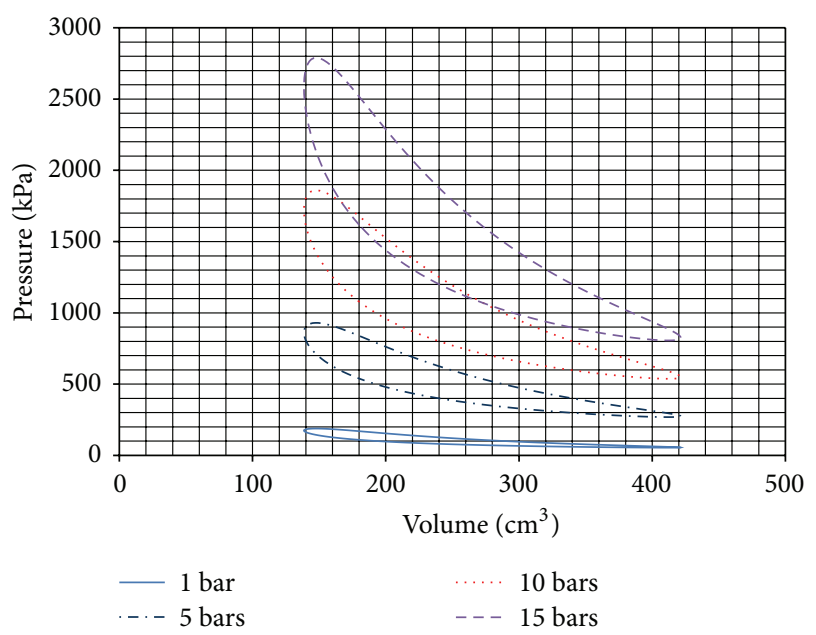

Figure 12: $P-V$ diagram at different operating pressures.

The brake specific fuel consumption without Stirling engine and with Stirling engine is displayed in Figure 11. At beginning of engine loading, bs.f.c. for internal combustion engine with and without Stirling engine are identical due to lowering in exhaust temperature (low load); subsequently when the engine load was increased, exhaust temperature will also increase, so Stirling engine will work effectively to reduce specific fuel consumption. So at those moments bs.f.c. curves are not identical.

Figure 12 displays the $P-V$ diagram at different operating pressures. The indicated work is represented by the area of enclosed curve for each operating pressure. As shown in the figure as the operating pressure increases, the area enclosed will increase and it will increase the indicated work.

\section{Conclusion}

The utilization of the exhaust waste heat for ICE by the use of Stirling engine was investigated. The study results can be summarized into the following points.

(i) Waste heat of internal combustion engine is considered great problem; two-thirds of that energy which entered through the engine was lost to the environment.

(ii) Waste heat recovery takes great benefits as raising fuel mileage and reducing greenhouse gases and fuel consumption, so that the IC efficiency will be increased.

(iii) Around 15\% can be improved in vehicle fuel economy through installing Stirling engine cross exhaust manifold to recover waste heat in internal combustion engines.

(iv) The recovered power through Stirling engine can be converted to charge vehicle's batteries or to operate the mechanical auxiliary such as oil pump, water pump, A/C compressor, and power steering pump.

(v) Applications' range for this project is not trapped on the automobile only, but it can be applicable on electricity generation planets, mining application cement planets, and factories.

(vi) Three obstacles to using Stirling engine are as follows: (1) adding some weights to the automobile which is going to decrease its fuel efficiency, so in order to be viable it must be light; (2) backpressure through the exhaust system; (3) additional pumping power losses.

\section{Conflict of Interests}

The authors declare that there is no conflict of interests regarding the publication of this paper.

\section{References}

[1] J. Halderman, Automotive Technology, Prentice Hall, 4th edition, 2011.

[2] J. Jadhao and D. Thombare, "Review on exhaust gas heat recovery for I.C. engine," International Journal of Engineering and Innovative Technology, vol. 2, no. 12, pp. 93-100, 2013.

[3] N. Galanis, E. Cayer, P. Roy, E. S. Denis, and M. Désilets, "Electricity generation from low temperature sources," Journal of Applied Fluid Mechanics, vol. 2, no. 2, pp. 55-67, 2009.

[4] K. K. Srinivasan, P. J. Mago, and S. R. Krishnan, "Analysis of exhaust waste heat recovery from a dual fuel low temperature combustion engine using an Organic Rankine Cycle," Energy, vol. 35, no. 6, pp. 2387-2399, 2010.

[5] C. Lloyd, A low temperature differential stirling engine for power generation [M.S. thesis], Department of Electrical and Computer Engineering, University of Canterbury, 2009.

[6] U. Ramesh and T. Kalyani, "Improving the efficiency of marine power plant using stirling engine in waste heat recovery systems," International Journal of Innovative Research and Development, vol. 1, no. 10, pp. 449-466, 2012. 
[7] J. Ruiz, Waste heat recovery in automobile engines: potential solutions and benefits [Master dissertation], Department of Mechanical Engineering, Massachusetts Institute of Technology, 2007.

[8] K. Hirata, "Schmidt theory for Stirling engines," Tech. Rep., National Maritime Research Institute, 1997.

[9] M. Ehsan, M. Shah, H. Hasan, and S. Hasan, "Study of Temperature Profile in automotive exhaust systems for retrofitting catalytic converters," in Proceedings of the International Conference on Mechanical Engineering (ICME '05), Dhaka, Bangladesh, 2005. 




Journal of

Industrial Engineering
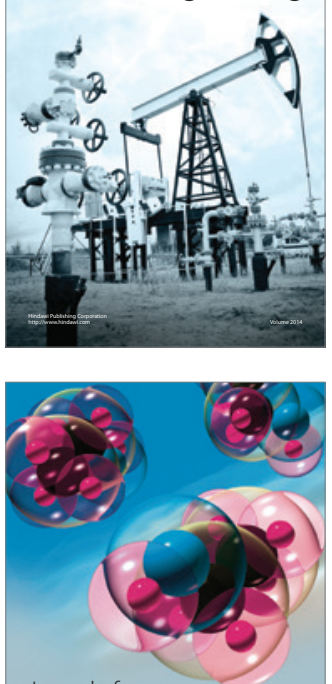

Fuels
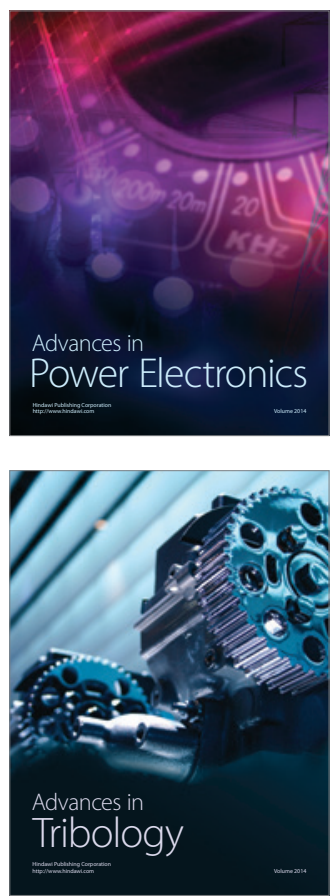

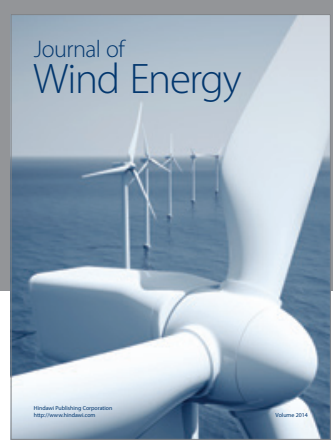

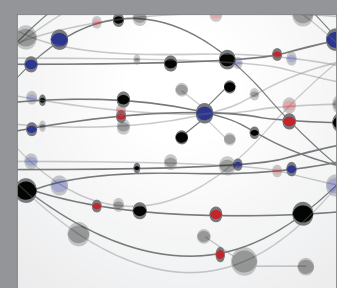

The Scientific World Journal

Submit your manuscripts at http://www.hindawi.com

Journal of

Structures
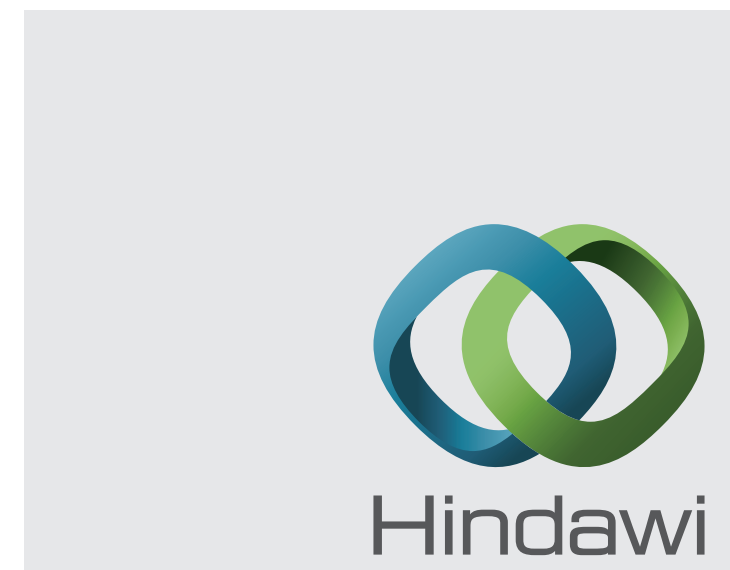

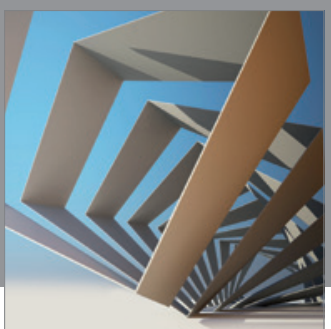

Rotating

Machinery
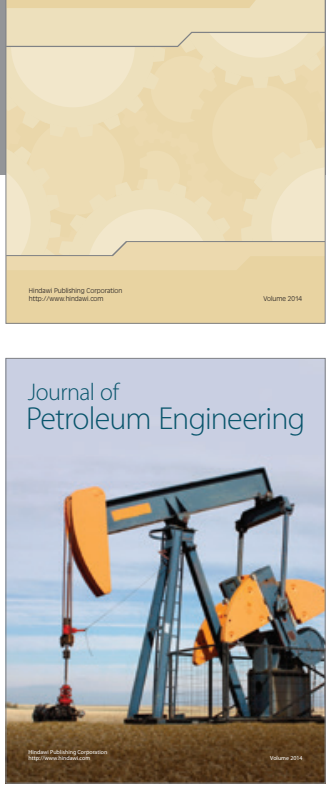

Journal of

Solar Energy
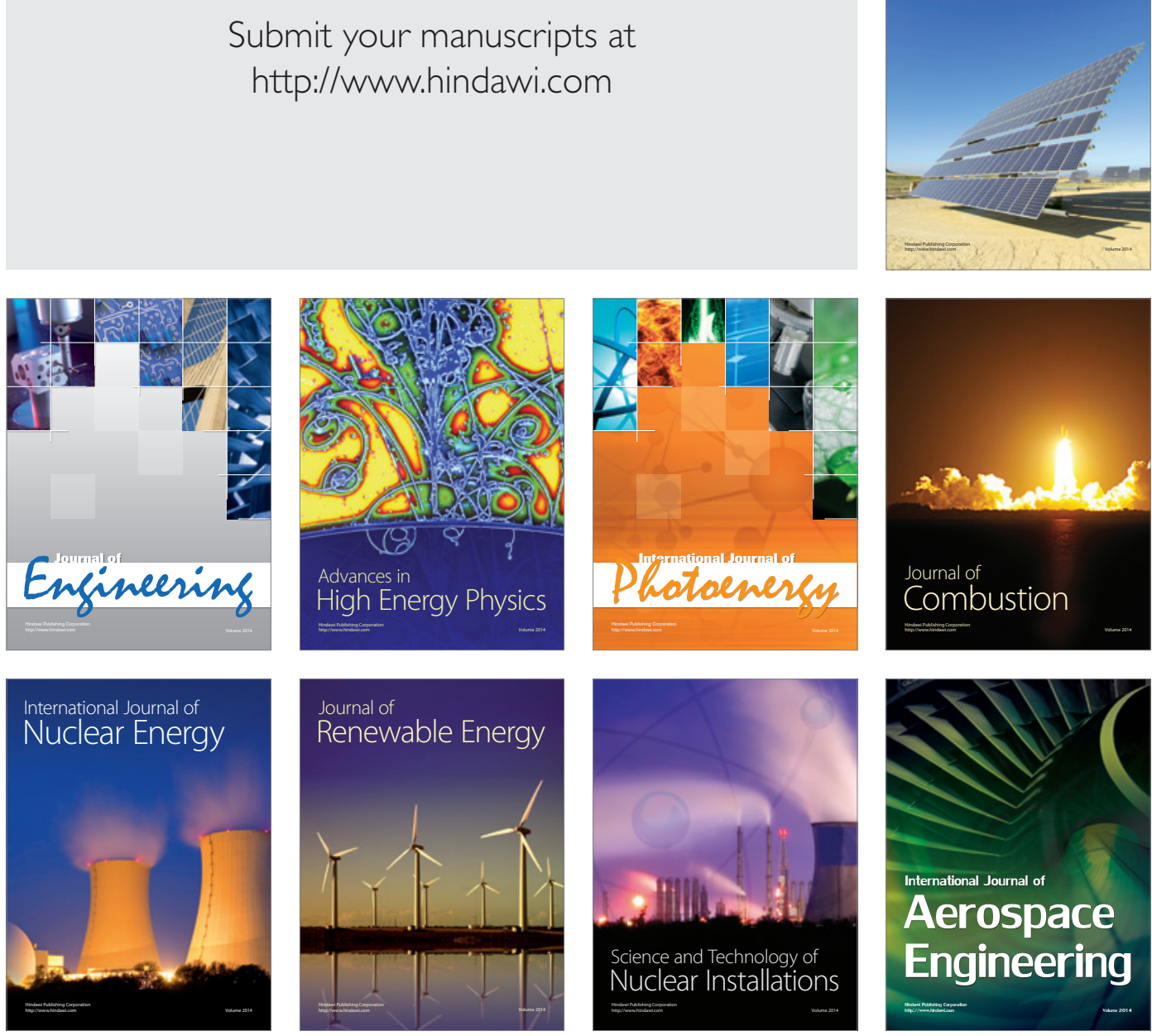